\title{
Phase Contrast Imaging of a Single Cell Expressing Cancer Markers in Its Specific Area Using Gold Nanoshells
}

\author{
Kyungmi Kim, Sangyeop Lee, Moonkwon Lee, Byunghee Han, Sungyong Kim, Jaebum Choo, \\ Soon Young Shin, ${ }^{+}$Young Han Lee, ${ }^{\ddagger}$ Dae-Gab Gweon, ${ }^{\$}$ and Chil-Hwan $\mathrm{Oh}^{\#}$ \\ Department of Applied Chemistry, Hanvang University, Ansan $426-791$, Korea, " E-mail: jbchooghanang ac.kr \\ ${ }^{\dagger}$ Institute of Aatural Science \& Technologv, Hanvang University, Ansan +26-791, Korea \\ ${ }^{\ddagger}$ Department of Biomedical Science \& Technologr, Konkuk Liniversitw, Seoul 143-701, Korea \\ sDepartment of Mechanical Engineering, KAIST, Daejeon 305-701, Korea \\ "Department of Dermatologv, Korea Lniversity, Seoul 136-174, Korea \\ Received February 11, 2007
}

Key Words : Phase contrast imaging. Optical imaging. Gold nanoshell. ERK2 marker. PLC $\gamma 1$ marker

Molecular imaging technology using metal nanoparticles has been extensively applied to biomedical diagnostics. For example. fluorescence imaging using Quantum Dot (QD) nanocrystals ${ }^{1}$ and surface-enhanced Raman imaging using gold nanoparticles ${ }^{2}$ are extensively used for sensitive and selective biomarker inaging in cells and tissues. Recently. scattering-based phase contrast optical imaging technique is energing as a new optical visualization tool for in vivo biomedical imaging. This technique provides a fast and costeffective high resolution inaging method compared with current expensive imaging modalities. To better improve spatial resolution in phase contrast optical imaging. gold nanoshells are used as contrast agents. Gold nanoshells constitute a novel kind of optically tunable nanoparticle consisting of a dielectric silica core surrounded by a thin gold layer. Gold nanoshells offer a variety of biomedical applications. such as blood inmunoassay. ${ }^{3}$ photothermal cancer therapy ${ }^{4}$ and X-ray computed tomography. ${ }^{5}$ Recently. Loo et al.$^{\circ}$ used gold nanoshell bioconjugates as contrast agents to improve the resolution of a phase contrast optical image. They used a dark field microscope to demonstrate the feasibility of nanoshell bioconjugates for targeting and imaging the biomarker. human epidermal growth factor receptor 2 (HER2), in live human breast $\mathrm{SKBr}_{3}$ breast cancer cells. In this work. low magnification $(\times 10$ and $\times 40)$ dark field images for 50-60 cells were obtained and, only an average scattering intensity value for nanoshell-labeled cells could be evaluated. However. a highly resolved optical image. down to a single cell level. is very important to understand the mechanism of disease markers' expression in its specific area. For this purpose. in the present study. a high magnification $(\times 100)$ phase contrast imaging technique using gold nanoshells has been used to obtain a sensitive cancer marker inage in a single cell level. As optical imaging targets. a $\mathrm{C} 6$ glyoma cell expressing ERK2 markers inside the cell and a human enbryouic kidney (HEK) 293 cell expressing PLC $\gamma 1$ markers on its surface membrane were used, respectively. It has been previously reported that overexpression of ERK2 protein is closely related to a cancer development or progression. ${ }^{7}$ Overexpression of
PLC $\gamma$ l marker is also closely associated with human hyperproliferative tissues, including breast carcinoma, colorectal carcinoma. and familial adenomatous polyposis. ${ }^{8,9}$ It is the main purpose of this conmunication to evaluate the feasibility of gold nanoshell bioconjugates for the highly resolved phase contrast imaging of a single cell expressing cancer markers in its specific area.

Gold nanoshells were fabricated by the process previously reported. ${ }^{1 i 1 / 13}$ Figure 1 shows the TEM and SEM images of $70 \mathrm{~nm}$ average diameter-size silica nanoparticles and gold/ silica nanoshells durng three stages of shell growth. Here, the gold shell thichness was estimated to be $20 \mathrm{~mm}$. First. very small gold metal particles were seeded onto the surface of silica. Then the gold seeds were grown to cover the whole silica surface via chemical reduction in solution. To attach the gold nanoshells selectively onto marker antibodies in

(a)
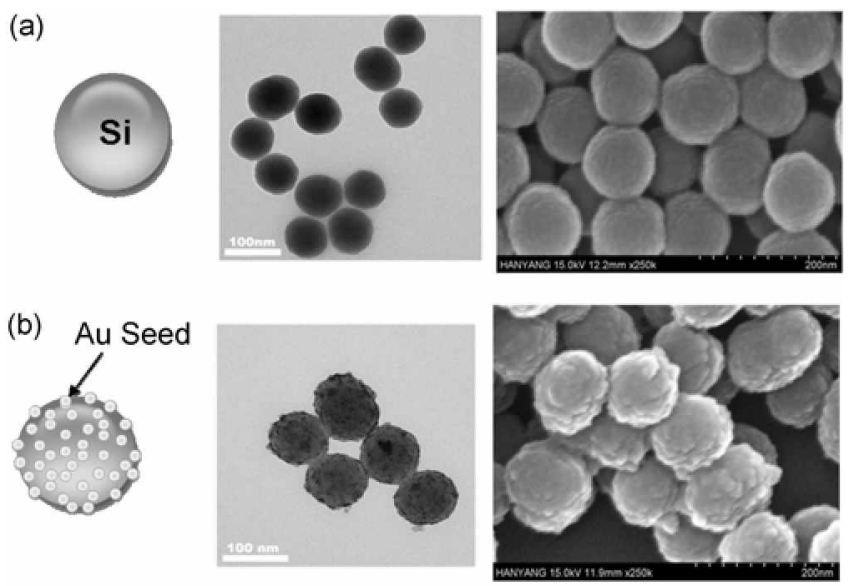

(c)
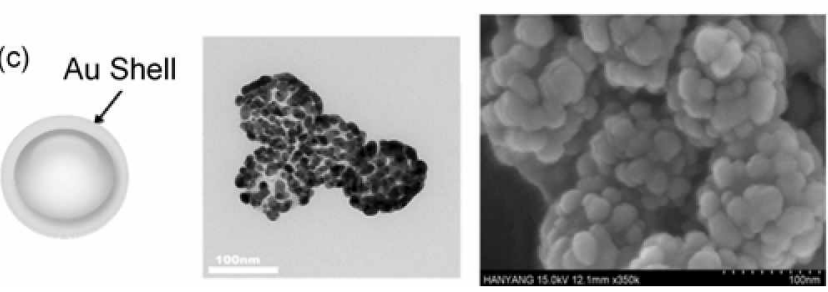

Figure 1. TEM and SEM images of (a) silica nanoparticles, (b) gold-seeded silica nanoparticles, and (c) gold-coated nanoshells. 
(a)

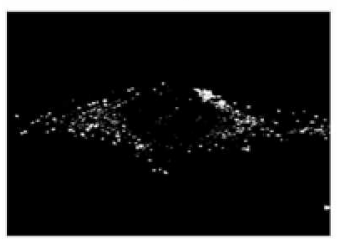

(b)

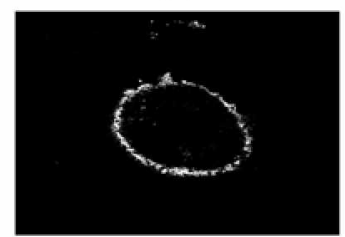

(c)

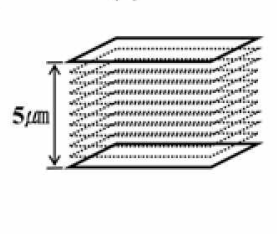

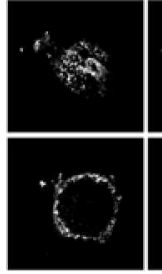

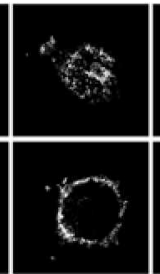

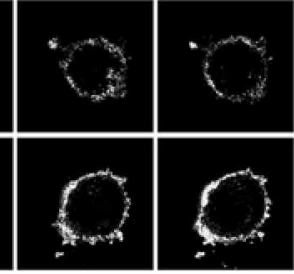

Figure 2. Phase contrast images of (a) an ERK2-expressing C6 glyoma cell in its cytoplasm area, (b) a PLC $\gamma$ l-expressing HEK293 cell on its surface membrane, and (c) Serial optical sections of a PLC $\gamma$-expressing HEK293 cell using gold nanoshells. The $z$-axis interval tor the optical slices is $500 \mathrm{~mm}$. Cells were incubated for $30 \mathrm{~min}$ on gold nanoshells, after which the free gold nanoshells were washed away.

cells. anti-mouse IgG was conjugated to the nanoshell surface. Ortho-pyridyldisulfide-polyethylene glycol- $N$-succinimidyl propionate (OPSS-PEG-NHS) was used for the antibody conjugation. ${ }^{4,6,11}$ The S-S terminal group of orthopyridyldisulfide was cleaved and chenically bonded onto the metal surface. The other terminal group, $N$-succininidyl propionate. was bound to an anine group on the antibody. Anti-mouse IgG-labeled nanoshells could be obtained by the reaction between nanoshells and PEG-labeled anti-nouse $\operatorname{lgG}(1 \mathrm{mg} / \mathrm{mL}$ ) for $\mathrm{l} \mathrm{h}$. The remaining nonspecific adsorption sites were coated with $1.4 \mu \mathrm{M}$ SH-PEG to prevent their aggregation. Phase contrast reflectance images of nanoshelllabeled cells were collected with a Leica TCS SL confocal inicroscope

First. ERK2 markers were expressed in the cy toplasn area of a C6 glyoma cell. Figure 2(a) shows the phase contrast image of an ERK2-expressing C6 glyoma cell in its cytoplasm area. A highly scattering cell image for the marker expressed cytoplasm area could be easily identified. Second, PLC $\gamma \mathrm{l}$ markers were expressed on the surface membrane of a HEK 293 cell. Figure 2(b) displays the phase contrast image of a PLC $\gamma 1$-expressing HEK293 cell. The anti-mouse IgG-conjugated nanoshells were effectively attached to the cancer cells on which the PLC $\gamma l$ markers were expressed and a clear gold color phase contrast inage was observed. To demonstrate that the markers are only expressed on the surface membrane. 10 optical sections for a HEK293 cell expressing PLC $\gamma$ l were obtained using a confocal microscope. As shown in Figure 2(c). optical sections from 10 confocal planes (corresponding to a distance between planes of $500 \mathrm{~nm}$ ) reveal that the marker is only expressed on the surface membrane. Our results demonstrate that the phase contrast imaging technology using gold nanoshells can be applied to a highly sensitive imaging of biomarkers in the specific area of a single cancer cell. In particular the scattering-based phase contrast imaging technique is a very simple and cost-effective process compared with the rather complicated fluorescence or Raman inaging techniques.

Acknowledgements. This work was supported by the National Cancer Center of Korea (grant number $062040(1-1)$ and the Seoul Research and Business Development Program (grant number 10574). We thank the MOCIE for a grant from the Strategic National R\&D Program. M.L. and S.L. acknowledge the fellowship from Seoul City. J.C. also thanks Hanyang University for financial support during the 2006 academic year

\section{References}

1. Gao. X.: Cui, Y.: Levenson, R. M.: Chung. L. W. K.: Nie, S. Nat. Biotechol. 2004, 22.969.

2. Kneipp. I.: Kneipp. H.: Rice. W. L.: Kneipp. K. Anal. Chen. 2005. 77. 2381

3. Hirsch. L. R.: Jackson. J. B.: Lee. A.: Halas. N. J.: West. J. L. Anal. Chem. 2003, 75. 2377.

4. Loo. C.: Lowery. A.; Halas. N. J.: West. J:- Drezek. R. Namo Lett $2005.5,709$.

5. Rabin. (๖.: Perez. J. M.: Grimm. J.: Wojtkiewicz. G.: Weissleder. R. Nature Mater 2006. 5.118.

6. Loo. C.: Hirsch. L.: Chang. E.: West. J.: Halas. N. T.: Drezek. R. Opt. Lett. 2005. 30.1012.

7. Yano. T.: Yano, Y: Nagashima. Y. Life Sci. 1999. 64. 229.

8. Lee. S.: Kim. S.: Choo, J :- Shin, S. Y.: Lee. Y. H.; Choi, H. Y.: Ha. S.: Kantg. K.: Oh. C. H. Anal Chent 2007. 79.916.

9. Shit1. S. Y.: Ko. J.: Chan1g. T. S.: Min. D. S.: Choi. C.: Bae. S. S.: Kim. M. I.: Hyun. D. S.: Kim. J. H.: Han1. M. Y.: Kim. Y. H.: Kim. Y. S.: Na. D. S.: Sul, P. G.: Lee, Y. H. FEBS Lett. 2002, 16. 1504.

10. Loo. C.: Lin, A; Hirsch, L.: Lee, M. H.; Barton, J.: Halas. N. J.; West, J.; Drezek, R. Tech. Cancer Res. \& Treat. 2004, 3.33.

11. Hirsch. L. R.: Statford. R. J.: Banksonl. J. A.: Sershent. S. R.: Rivera. B.: Price. R. E.: Hazle. T. D.: Halas. N. J. Proc. Nall Acad. Sci. L. S. A. 2003. 100. 13549 .

12. Oldenturg, S. J; Averitt. R. D; Westcott. S. L.: Halas, N. J. Chem. Phys. Lett. 1998. 288, 243.

13. Park. S.-E.; Park, M.-Y.: Han. P.-K; Lee, S.-W. Bull. Kor Chem Soc. 20106.27 .1341$. 